\title{
sciendo
}

Current Issues in Pharmacy and Medical Sciences

Formerly ANNALES UNIVERSITATIS MARIAE CURIE-SKLODOWSKA, SECTIO DDD, PHARMACIA

\section{Proteolytic parameter changes in the plasma of patients with bladder cancer - depending on tumor stage}

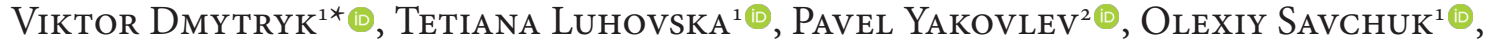

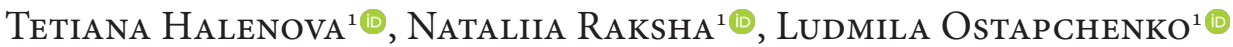

${ }^{1}$ ESC "The Institute of Biology and Medicine", Taras Shevchenko National University of Kyiv, Ukraine

2 Department of Urology, O. Bogomolets National Medical University, Kyiv, Ukraine

\section{ARTICLE INFO \\ Received 28 May 2019 \\ Accepted 12 August 2019}

\section{Keywords:}

bladder cancer,

serine proteases,

MMPs,

$\alpha 1 \mathrm{~A}$,

$\alpha 2 \mathrm{M}$,

medium mass molecules.

\section{ABSTRACT}

Bladder cancer (BC) is a worldwide common disease with a high mortality rate. Recognizing the dynamic changes in plasma that proteases and their inhibitors undergo might be valuable in understanding the carcinogenesis of invasive bladder cancer and in identifying BC patients with poor prognosis. This study aims to determine the activity of the proteolytic enzyme system and their inhibitors in patients with BC. In this paper, the total proteolytic activity, the activity of matrix metalloproteases (MMPs) and serine proteases was analyzed by the method of caseinolytic activity. For detection of activity of some inhibitors of proteolysis, we used the unified method for determining the activity of alpha-1-antitrypsin ( $\alpha 1 \mathrm{~A})$ and alpha-2-Macroglobulin ( $\alpha 2 \mathrm{M}$ ) in human plasma. The level of medium-mass molecules (MMM) was assessed spectrophotometrically by applying the Nikolaichik method.

The activity of MMPs was elevated in all groups of patients. Moreover, the activity of serine proteases was found to be enhanced in patients with Stage I, III and IV BC, while the activity of $\alpha 1 \mathrm{~A}$ was up by 1.4 and 1.3 times in patients with Stage I and Stage IV. The most significant increase was observed with regard to the activity of $\alpha 2 \mathrm{M}$ in patients with I and III stages of BC. In addition, the level of MMM correlated with cancer stage. Indeed, the highest increase in the activity of protease inhibitors was observed in Stage I bladder cancer patients, which might signify their protective role at the onset of the bladder carcinogenesis. In contrast, significant growth in activity of $\alpha 2 \mathrm{M}$ in patients with III stage of BC may point at a compensatory mechanism that inhibits tumor growth.
\end{abstract}

\section{INTRODUCTION}

Bladder cancer $(\mathrm{BC})$ is a common worldwide disease [1]. Indeed, $\mathrm{BC}$ is the ninth most frequently diagnosed cancer globally, with the highest incidence rates observed in developed countries. About $75 \%$ of all patients with BC are men [2]. In the progress of the disease, proteases trigger biochemical processes by selective proteolysis of different polypeptides. Moreover, they participate in interactions and amplification cascades (deemed the 'protease web'). Blood plasma contains several complex proteolytic systems that participate in the protective and regulatory reactions of the body [3]. These systems interact with the cascade regulation principle, which allows, if necessary, to significantly accelerate the physiological processes in the body,

\footnotetext{
* Corresponding author

e-mail: victordmytryk@gmail.com
}

and also to regulate them with specific inhibitor proteins at each stage [4].

It is a known fact that tumor invasion in surrounding tissues is accompanied by local secretion of proteolytic enzymes by tumor cells. Proteolysis involves the breakdown of proteins into smaller polypeptides or amino acids through the hydrolysis of peptide bonds by a protease. However, the role of medium-mass molecules (MMM) as the products of proteolysis in the development of bladder cancer disease has not been studied. Parameters of the content of MMM that are products of excessive proteolysis can serve as an indicator of $\mathrm{BC}$ progression and may be involved in the pathogenesis of the disease. Proteases provide favorable conditions for invasion by destroying the intercellular matrix proteins [5]. Proteolytic activity is affected not only by the formation rate of proteases, but also by their inactivation with specific inhibitors. Studies of the proteolytic system 
can, hence, be perspective for improving laboratory methods of early cancer diagnostic.

The present work aims to investigate specific features of the proteolytic enzymes system, their inhibitors and level of $\mathrm{MMM}$ in patients with $\mathrm{BC}$ at different stages.

\section{MATERIAL AND METHODS}

This study enrolled 29 bladder cancer patients (27 males, 2 females), aged from 52-76 years. All patients underwent standard preoperative study, including blood and urine analysis, blood chemistry and immunogram, computed tomography of chest, abdomen and pelvis (with contrast medium to assess the spread of cancer) and tumor biopsy with pathological evaluation. BC stages were set up by adhering to TNM clinical classification as following: Stage I in 9 patients; Stage II in 7 patients; Stage III in 7 patients; and Stage IV in 8 patients. All patients had transitional cell carcinoma of the bladder. The control group consisted of 30 healthy individuals ( 8 females and 22 males) of respective age (50-77). All donors and patients (or their respective relatives) were informed about the clinical research protocol. Informed consent was obtained by applying the Helsinki Declaration. The clinical research protocol was approved by the Ethics Committees of the ESC (Institute of Biology and Medicine) of Kyiv, Ukraine.

The total proteolytic activity was analyzed by applying the method of caseinolytic activity (with modifications). For determination of the selective activity of MMPs and serine proteases, $0.2 \mathrm{~mol} / 1$ ethylenediaminetetraacetic acid (EDTA) or phenylmethylsulphonyl fluoride (PMSF), respectively, were added to the reaction mixture (final concentration) [6]. Subsequently, $0.05 \mathrm{M}$ ( $\mathrm{pH}$ 7.4) phosphate buffer was added to $30 \mathrm{ml}$ of plasma to make up a volume of $1 \mathrm{ml}$. To 30 $\mathrm{ml}$ of plasma, $0.05 \mathrm{M}(\mathrm{pH}$ 7.4) phosphate buffer was then added to create a volume of $1 \mathrm{ml}$. The mixture was stirred and added to $1 \mathrm{ml}$ of $4 \%$ casein, and then incubated for 30 min in a water bath at $+37^{\circ} \mathrm{C}$. The reaction was stopped by introducing $3 \mathrm{ml}$ of $15 \%$ trichloroacetic acid, followed by centrifugation at $2000 \mathrm{rev} / \mathrm{min}$ for $30 \mathrm{~min}$. The supernatant was selected via optical density and measured at a wavelength of $280 \mathrm{~nm}$. The control sample consisted of a mixture of casein, phosphate buffer and respective trichloroacetic in identical proportions. To prepare $4 \%$ casein reagent, a sample weighing 4 grams was dissolved in $80 \mathrm{ml} 0.05 \mathrm{M}$ phosphate buffer $\mathrm{pH} 7.4$ and $1.6 \mathrm{ml} 1 \mathrm{M}$ sodium hydroxide. The mixture was left at room temperature for $40 \mathrm{~min}$ for swelling and was then boiled 15 minutes in a water bath. Once cooled, casein $\mathrm{Ph}$ was adjusted to 7.4 and $1 \mathrm{M}$ sodium hydroxide volume was adjusted to $100 \mathrm{ml}$ phosphate buffer.

The activity of $\alpha 1 \mathrm{~A}$ and $\alpha 2 \mathrm{M}$ was determined using the Nartykova method [7], while the activity of $\alpha 1 \mathrm{~A}$ was determined by the method of inhibition of the arginine-esterase activity of trypsin. Here, Ethyl N2-benzoyl-L-argininate hydrochloride (1:1) (BAEE) was used as a substrate. Two experimental samples were prepared; the first contained $1.9 \mathrm{ml}$ of $0.05 \mathrm{M}$ Tris- $\mathrm{HCl}$ buffer and $0.1 \mathrm{ml}$ of $0.01 \%$ trypsin solution, and the second contained $1.8 \mathrm{ml}$ of $0.05 \mathrm{M}$ Tris- $\mathrm{HCl}$ buffer, $0.1 \mathrm{ml}$ of the $0,01 \%$ solution of trypsin and $0.1 \mathrm{ml}$ of plasma (diluted 50 times). The mixture was kept for 5 minutes at $+25^{\circ} \mathrm{C}$, then $1 \mathrm{ml}$ of $1.5 \mathrm{mM}$ BAEE solution was added. Following this, the increase in optical density at a wavelength of $253 \mathrm{~nm}$ for measured for 3 minutes, and from the linear graph of the reaction, an increase in optical density $\Delta \mathrm{D}_{253}$ for $1 \mathrm{~min}$ was found for the experimental and control samples. The difference between the values of the experimental and control samples was used to calculate the activity of $\alpha 1 \mathrm{~A}$ by applying the formula:

$$
\begin{gathered}
\left(\mathrm{V}_{0}-\mathrm{V}_{\mathrm{i}}\right) \cdot 2.73 \cdot 50 / 0.01=\text { number of inhibitory units } \\
\text { per } 1 \mathrm{ml} \text { of plasma }(\mathrm{IU} / \mathrm{ml})
\end{gathered}
$$

where $\mathrm{V}_{0}$ and $\mathrm{V}_{\mathrm{i}}$ are the rates of hydrolysis of BAEE with trypsin in the control and experimental samples, respectively, and equal to the increase in optical density $\Delta \mathrm{D}_{253}$ for $1 \mathrm{~min} ; 2.73$ is the calculated coefficient for ascertaining the amount of BAEE hydrolyzed in the sample under the given conditions (in $\mu \mathrm{mol}$ ); 0.1 - the amount of blood plasma taken for analysis (ml); 50 - dilution factor.

The activity of $\alpha 2 \mathrm{M}$ was determined by utilizing the spectrophotometric method. Here, we measured the arginineesterase activity of the complex of trypsin utilizing the $\alpha 2 \mathrm{M}$ that is formed after the interaction of an excess of trypsin with blood plasma that was diluted ten times. After this, the applied soy inhibitor inactivates free trypsin (which is not bonded with $\alpha 2 \mathrm{M}$ ). Herein, to $1.75 \mathrm{ml}$ of $0.05 \mathrm{M}$ Tris-HC1buffer $\mathrm{pH} 8.0$, we introduced $0.1 \mathrm{ml}$ of plasma (diluted 10 times) and $0.05 \mathrm{ml}$ of trypsin solution $(50 \mu \mathrm{g})$; The reaction mixture was subsequently incubated for 5 minutes at $+25^{\circ} \mathrm{C}$, after which $0.1 \mathrm{ml}$ of a soy inhibitor solution $(300 \mu \mathrm{g})$ was added. The contents of the cuvette were then mixed and increased by $1 \mathrm{ml}$ of $1.5 \mathrm{mM}$ BAEE solution. Subsequently, the increase in optical density at $253 \mathrm{~nm}$ was measured for 10 minutes against a control sample that contained only $2 \mathrm{ml}$ of Tris- $\mathrm{HCl}$ buffer and $1 \mathrm{ml}$ of BAEE solution. The activity of $\alpha 2 \mathrm{M}$ was expressed in standard units in $1 \mathrm{ml}$ of plasma and was calculated using the following formula:

$$
\Delta \mathrm{D}_{253} \cdot 2.73 \cdot 10 / 0.1 \cdot 10=\Delta \mathrm{D}_{253} \cdot 27.3=(\mathrm{IU} / \mathrm{ml})
$$

where $\Delta \mathrm{D}_{253}$ is the increase in optical density in a sample for $10 \mathrm{~min}$, while 2.73 - the estimated coefficient; 10 measurement time ( $\mathrm{min})$.

The level of MMM was measured by applying the Nikolaichik method [8]. To the centrifuge tubes, we added plasma and chloric acid stirred in a ratio of 1:1.2 and centrifuged for $30 \mathrm{~min}$. at $3000 \mathrm{rev} / \mathrm{min}$. This was then held for $20 \mathrm{~min}$ at a temperature of $+4^{\circ} \mathrm{C}$, and subsequently centrifuged at 7,000 rpm for $15 \mathrm{~min}$. To the supernatant we then added $5 \cdot 10 \mathrm{H} \mathrm{KOH}$. Afterwards, the supernatant was pre-suspended with $96 \%$ alcohol, and subsequently centrifuged at 7,000 rpm for $15 \mathrm{~min}$. The supernatant was then collected and diluted 10 times with distilled water. The content of the test tube was stirred and measured at $254 \mathrm{~nm}$.

The statistical analysis of the obtained results was performed using the methods of variation statistics and correlation analysis. To determine the reliability of the differences between the two samples, we used the Student test $(\mathrm{t})$. The results were considered reliable at $\mathrm{p}<0.05$. 


\section{RESULTS}

Total proteolytic activity in plasma from patients with BC Stages I, III and IV was higher compared to controls by 1.3 , 2 and 1.4 times, respectively (Figure 1). Furthermore, the activity of MMPs in plasma from patients with BC Stages II, III was increased by 2 and 1.9 times, while that of individuals at Stages I, IV was higher by 1.6 and 1.4 times, respectively. In addition, serine protease activity in plasma from patients with BC Stages I, III and IV were increased by $2.1,2.5$ and 1.3 times, respectively (Figure 1 ).
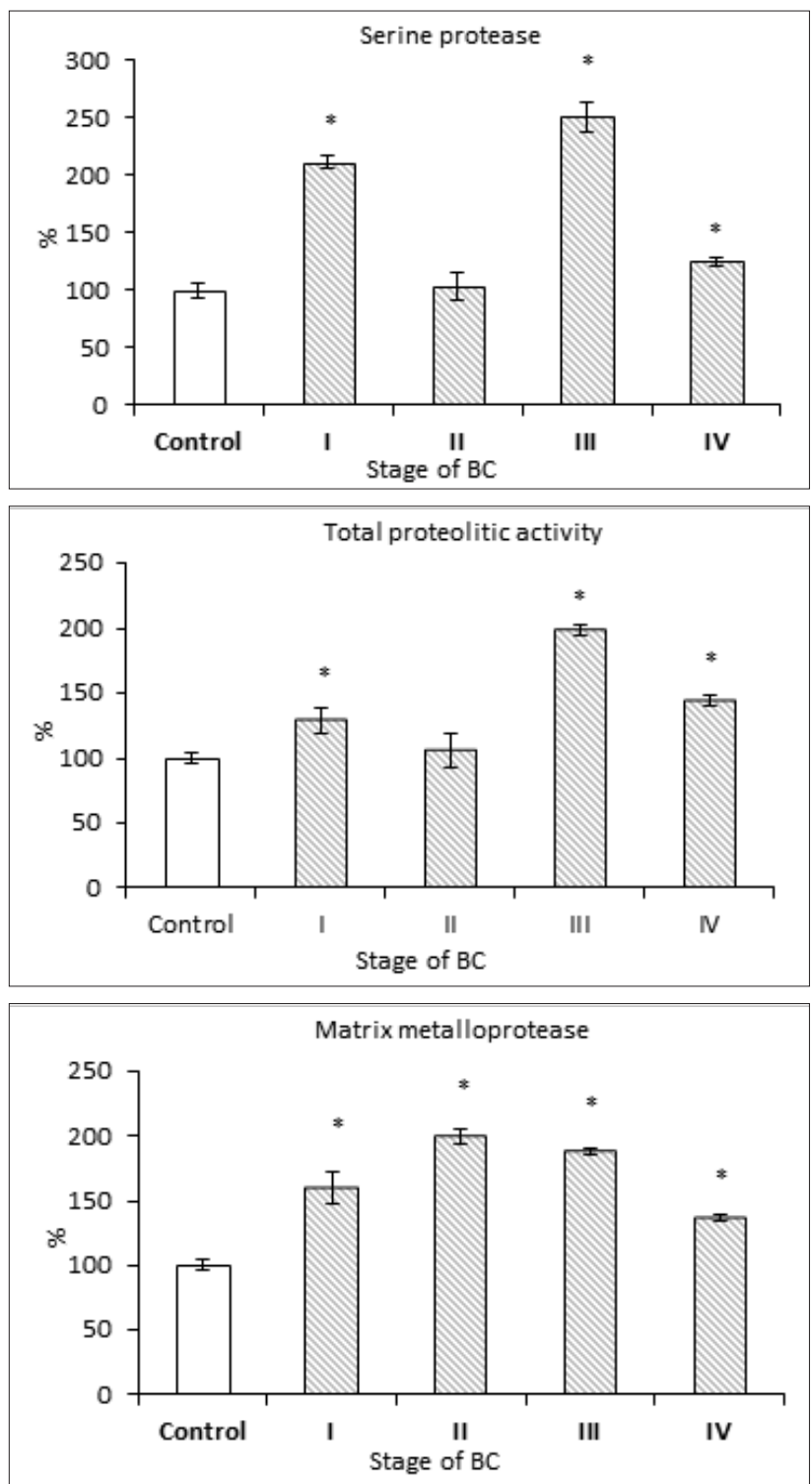

$*_{\mathrm{p}}<0.05$ compared with the control value

Figure 1. Total proteolytic activity, Matrix metalloprotease activity,and Serine protease activity (\%) in plasma from patients with BC (mean (SD))

What is more, plasma activity of $\alpha 1 \mathrm{~A}$ was higher by 1.4 and 1.3 times in patients with BC Stages I and IV. However, the activity of $\alpha 1 \mathrm{~A}$ was decreased compared to controls by 1.3 times in patients with BC Stage III. In addition, plasma activity of $\alpha 2 \mathrm{M}$ was significantly higher (by 3 and 3.6 times) in patients with BC Stages I and III, compared to controls, while in patients with Stages II and IV BC, activity of $\alpha 2 \mathrm{M}$ was increased by 1.7 and 1.4 times, respectively (Figure 2).
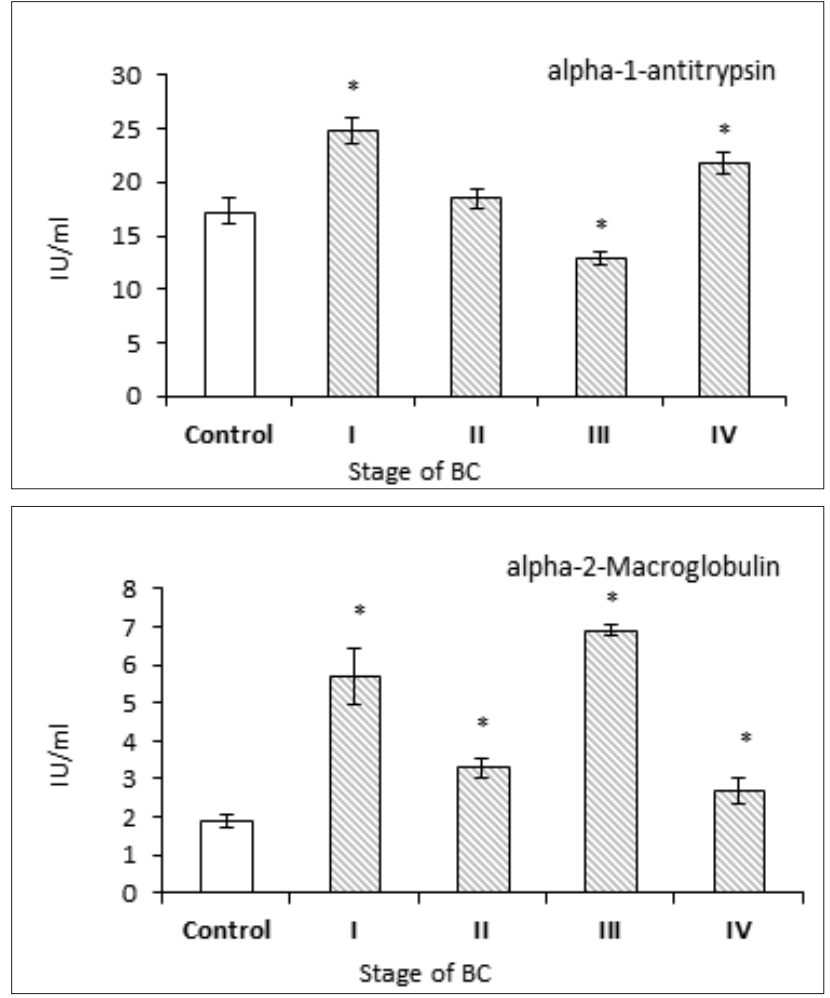

${ }^{*} \mathrm{p}<0.05$ compared with the control value

Figure 2. The activity of $\alpha 1 \mathrm{~A}(\mathrm{IU} / \mathrm{ml})$ and $\alpha 2 \mathrm{M}(\mathrm{IU} / \mathrm{ml})$ in plasma from patients with $\mathrm{BC}$ (mean (SD))

The levels of MMM in plasma were determined at the next stage of this study. Herein, we discovered that the concentration of MMM was increased in direct dependence of the stage of BC. Accordingly, plasma levels of MMM in patients with BC Stage I, II and III was higher by 1.7, 2.2, 2.7, respectively. In patients with BC Stage IV, level of MMM was significantly higher (by 3 times) compared to controls (Figure 3).

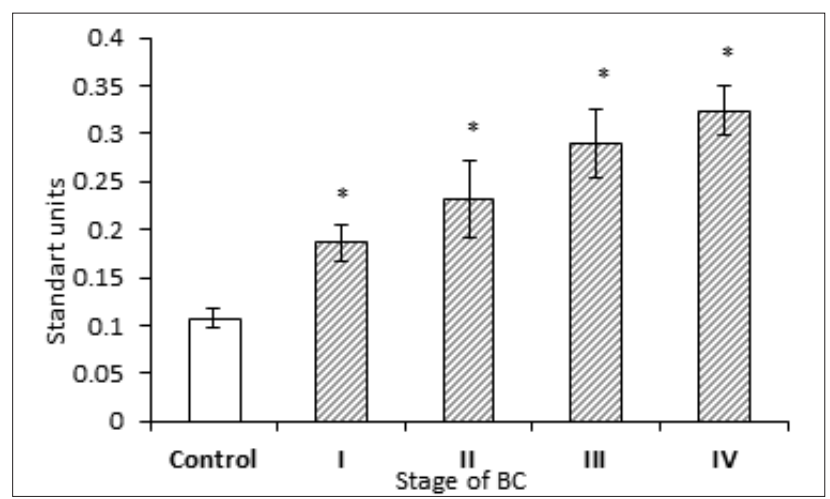

$* p<0.05$ compared with the control value

Figure 3. The level of medium-mass molecules (standard units) in plasma patients with BC (mean (SD))

\section{DISCUSSION}

Proteolytic enzymes are factors of progression in oncogenesis. Increased total proteolytic activity is associated with tumor invasion and this process provides proteases that are associated with tumor cells. Proteases stimulate angiogenesis and promote metastasis by destroying the extracellular matrix and basal membrane of healthy cells $[9,10]$. 
The role of serine proteases in oncogenesis is to activate other proteases of angiogenic and antiangiogenic growth factors. Serine proteases can both stimulate and inhibit the proliferation of malignant cells, and either support or repel invasion, metastasis, angiogenesis and proteolytic degradation of the extracellular matrix components in the area of a tumor. These enzymes catalyze the hydrolysis of a peptide bond [4], while serine proteases regulate neoplastic processes by activating transmembrane signal proteins, such as protease-activated receptors (PARs) $[4,11]$.

In these processes, in the tumor tissue, the proteolytic cascade activation of plasminogen (which belongs to the serine proteases) plays a central role both in the local spread of the tumor and in the progression of metastasis in distant tissues and organs. The process of plasmin formation generally is a cyclic amplification that is regulated by the principle of feedback. In the protease multistage chain that leads to the destruction of the extracellular matrix, the plasminogen activators of urokinase-type (uPa) and uPA receptors play key roles, and are present on the cell surface. When the plasminogen activator binds to it, the UPA ability to activate plasminogen is increased $[12,13]$.

Over the last years, the relevance of the MMPs family in cancer research has grown considerably. These enzymes were initially associated with the invasive properties of tumor cells, owing to their ability to degrade all major protein components of the extracellular matrix and basement membranes; however, further studies have demonstrated the implication of MMPs in the early steps of tumor evolution, including stimulation of cell proliferation and modulation of angiogenesis. MMPs allow local expansion of the tumor mass through the disruption of normal tissue structure and facilitate the invasion of blood vessels and lymphatics by metastatic cells, thus promoting tumor spread [14].

MMPs secretion and activation seem to result from a specific interaction between tumor and stromal cells. The breakdown of tissue architecture mediated by these activated enzymes allows the primary tumor to expand, invade the neighboring blood vessels and spread to distant sites in the body. Invasive growth in these secondary sites also appears to be facilitated by the action of MMPs [15].

Normally there is a dynamic equilibrium between proteolytic enzymes and their inhibitors. In pathological conditions, excessive activation of proteolysis is an important pathogenetic link in the development of destructive, inflammatory and allergic reactions, and one of the growth factors of malignant tumors [9]. The observed increase in inhibiting activity in plasma from patients with Stage I BC is probably a natural reaction to the activation of proteolysis and can be considered a protective mechanism against tumor invasion [16].

Zeyad El-Akawi, et al. have shown that the level of $\alpha 1 \mathrm{~A}$ increases in the blood serum of patients with oncological diseases, namely, cancer of gastrointestinal tract, prostate, bladder, brain, biliary tract, mammary glands and pancreatic adenocarcinoma [17]. Herein, $\alpha 2 \mathrm{M}$ was discovered to be a protein that can bind practically all known hydrolases without blocking their active center $[18,19]$. Furthermore, $\alpha 2 \mathrm{M}$ was found to transport biologically active compounds and regulate their binding to specific cell receptors, which gives it the properties of a universal immunoregulator [20].

The activity of this inhibitor was ascertained to increase due to the presence of macroglobulin (signal) receptors on the surface of tumor cells. The signal receptor initiates proliferation of target cells in reaction with $\alpha 2 \mathrm{M}$, by protein kinases activating and phosphorylation reactions. It is important to note that modified forms of $\alpha 2 \mathrm{M}$ are involved in the formation of complexes, and these forms can supply regulating substances to tumor cells $[21,22]$. In patients with IV stage BC, we observed a decrease in the activity of $\alpha 2 \mathrm{M}$ against the background of elevated $\alpha 1 \mathrm{~A}$ activity. A decline in $\alpha 2 \mathrm{M}$ activity is probably an unfavorable prognostic factor for a cancer patient, as it is known that $\alpha 2 \mathrm{M}$ bears cytotoxic property towards cancer cells. [23]. The direct antitumor activity of $\alpha 2 \mathrm{M}$ is effected via inhibiting the proliferation of transformed cells, while indirect activity is generated through the immune system.

The systemic effect of the tumor onto the body plays an important role in processes of oncogenesis. Tumor growth is accompanied by the development of endogenous intoxication, which result is the accumulation of intermediate and final products of disturbed metabolic processes in biological fluids and tissues. Among these products, that of MMM are predominant. Oncogenesis disturbs the balance between the synthesis of proteases and their inhibitors, resulting in increased proteolytic activity and increased concentration of MMM in the blood plasma [24].

MMM is a type of combination with molecular mass up to 5,000D. MMM are divided into two big groups - low and average molecular mass substances, mostly of non-protein origin, and oligopeptides (median-molecular peptides) with molecular weights not exceeding 10-15 kD [25,26]. MMM affect the condition and functioning of all systems and organs. The structure of MMM is similar to regulatory peptides that can connect and block cell receptors, thereby changing their functions and intracellular metabolism [27]. The concentration of MMM increases in the correlation with stages of oncogenesis and the severity of patients' conditions. Our research results show that MMM indicators can be valuable in predicting and diagnosing stages of bladder cancer. However, MMM cannot be used as molecular oncomarkers, since their concentration depends not only on the progress of carcinogenesis, but also on many other pathological conditions. Overall, however, it is possible to determine the intensity of tumor endotoxication, stage of oncogenesis and emergence of metastasis before surgical treatment by determining the degree of protease activity and the level of MMM concentration.

\section{CONCLUSION}

The variable activity of $\alpha 1 \mathrm{~A}$ and $\alpha 2 \mathrm{M}$ in plasma patients with different stages $\mathrm{BC}$ indicate the important role of these proteins in the pathogenesis of BC. Consequently, tumor growth and invasion are accompanied by activation of proteolysis system components in blood plasma. The concentration of inhibitors of these enzymes become higher in blood because this is an adequate response to increased protease activity. Such effect is especially visible in patients with BC 
Stage I. In contrast, in plasma patients with BC Stage III the increased activity of $\alpha 2 \mathrm{M}$ may indicate the activation of a compensatory mechanism that inhibits tumor growth. The results of studies of proteolysis indicators and endogenous intoxication in blood plasma indicate that these can be used for predicting oncogenesis and evaluating the effectiveness of treatment.

\section{ORCID iDs}

Viktor Dmytryk (1)https://orcid.org/0000-0002-4430-4511 Tetiana Luhovska (1)https://orcid.org/0000-0001-5068-5106 Pavel Yakovlev (1) https://orcid.org/0000-0002-1767-3231 Olexiy Savchuk (D) https://orcid.org/0000-0003-3621-6981 Tetiana Halenova (1) https://orcid.org/0000-0003-2973-2646 Nataliia Raksha (Dhttps://orcid.org/0000-0001-6654-771X Ludmila Ostapchenko (Dhttps://orcid.org/0000-0001-7181-6048

\section{REFERENCES}

1. Ploeg M, Aben KK, Kiemeney LA. The present and future burden of urinary bladder cancer in the world. World J Urol. 2009;27(3):289-93.

2. Murta-Nascimento C, Schmitz-Dräger BJ, Zeegers MP, Kogevinas G, Steineck M, Real FX, Malats N. Epidemiology of urinary bladder cancer: from tumor development to patient's death. World J Urol. 2007;25:285-95

3. Aggarwal N, Sloane BF. Cathepsin B: multiple roles in cancer. Proteomics Clin Appl. 2014;8(5-6):427-37.

4. Wolf K, Friedl P. Extracellular matrix determinants of proteolytic and non-proteolytic cell migration. Trends Cell Biol. 2011;21(12):736-44.

5. Heutinck KM, Berge IJ, Hack CE, Hamann J, Rowshani AT. Serine proteases of the human immune system in health and disease. $\mathrm{Mol}$ Immunol. 2010;47(11-12):1943-55

6. Hummel BC. Amodified spectrophotometric determination of chymotrypsin, trypsin and thrombin. Can J Biochem and Physiol. 1959;37:1393-9.

7. Nartykova VF, Paskhina TS. Unified method for determining the activity of a1-antitrypsin and $\alpha 2$-macroglobulin in serum (plasma) of human blood. Questions Med Chem. 1979;25(4):494-9.

8. Nikolaichik VV, Moin VM, Kirasky VV. A method for the detection of "meddle-size molecules". Lab Delo. 1993;10:11-8.

9. Hoffman BD, Grashoff C, Schwartz MA. Dynamic molecular processes mediate cellular mechanotransduction. Nature. 2011;475:316-23

10. Pranjol MZ, Gutowski N, Hannemann M, Whatmore J. The potential role of the proteases cathepsin $\mathrm{D}$ and cathepsin $\mathrm{L}$ in the progression and metastasis of epithelial ovarian cancer. Biomolecules. 2015;5(4):3260-79.
11. Wojtukiewicz MZ, Hempel D, Sierko E, Tucker SC, Honn KV. Protease-activated receptors (PARs)--biology and role in cancer invasion and metastasis. Cancer Metastasis Rev. 2015;34(4):775-96.

12. Pavón MS, Arroyo-Solera I, Céspedes MV, Casanova I, León $\mathrm{X}$, Mangues R. Silencing of plasminogen activator inhibitor-1 suppresses colorectal cancer progression and liver metastasis. Surgery. 2015;158(6):1704-13.

13. Mason SD, Joyce JA. Proteolytic networks in cancer. Trends Cell Biol. 2011;21(4):228-37.

14. Ulrich D, Ulrich F, Unglaub F, Piatkowski A, Pallua N. Matrix metalloproteinases and tissue inhibitors of metalloproteinases in patients with different types of scars and keloids. J Plast Reconstr Aesthet Surg. 2010;63(6):1015-21.

15. Rakashanda S, Rana F, Rafiq S, Masood A, Amin S. Role of proteases in cancer: A review. Biotechnol Mol Biol Rev. 2012;7(4):90-101.

16. Anariba DEI. Alpha1-Antitrypsin Deficiency. Medscape Reference. 2017. Available online at http://emedicine.medscape.com/ article/295686-overview. Accessed February 2017.

17. El-Akawi ZJ, Nusier MK, Sawalha DH. Alpha-1 antitrypsin genotypes in breast cancer patients. J Health Sci. 2008;54(4):493-6.

18. Ahmed A Rehman, Haseeb Ahsan, Fahim HK. Alpha-2macroglobulin: A physiological guardian. J Cell Physiol. 2013;228(8):1665-75.

19. Ferrer IG, Marrero A, Xavier F, Gomis-Rüth, Goulas T. a2-Macroglobulins: Structure and Function. Macromolecular Protein Complexes. 2017;83:14983.

20. Scherbina IN. The study of the diagnostic value of immunoregulatory proteins to assess the functional capacity of the fetoplacental complex with intrauterine infection. Br J Educ Scient Stud. 2016;1(23):833-8.

21. Rehman AA, Ahsan H, Khan FH. Alpha-2-macroglobulin: a physiological guardian. J Cell Physiol. 2013;228:1665-75.

22. Zorin NA, Zorina VN, Zorina RM. Role of proteins of the macroglobulin family in regulation of tumor growth. Ontogenez. 2006;37(1):12-9.

23. Lindner L, Hemdan NYA, Buchold M, Huse K, Bigl M, Oerlecke I, et al. a2-Macroglobulin inhibits the malignant properties of astrocytoma cells by impeding $\beta$-Catenin signaling. Ther Targets Chem Biol. 2010;70(1):277-87.

24. Korobov V, Bolesta I, Dika A, Korobova O, Savitsky V. Optical analysis of middle-molecular mass molecules of blood of individuals suffering from myocardial ischemia. Ukr J Phys Opt. 2012;3(1):35-42.

25. Chmielewski M, Cohen G, Wiecek A, Carrero J. The peptidic middle molecules: is a molecular weight doing the trick? Semin Nephrol. 2014;34:118-34.

26. Ishchuk TV, Raetska YaB, Savchuk OM, Ostapchenko LI. Changes blood protein composition under experimental chemical burns of esophageal development in rats. Biomed Res Ther. 2015;3(4):241-9.

27. Nagoev BS, Nagoeva MK. Implication of middle-mass molecule peptides of blood plasma in assessment of intoxication syndrome in patients with bacterial tonsillitis. Vestn Otorinolaringol. 2016;6:41-4. 